\title{
Correlation Study of the Long-Term Prognosis of Venous Thromboembolism and Inflammatory Gene Polymorphisms
}

This article was published in the following Dove Press journal: International Journal of General Medicine

\section{Refukaiti Abuduhalike Juan Sun \\ Ailiman Mahemuti}

Department of Cardiovascular Medicine, The First Affiliated Hospital of Xinjiang Medical University, Urumqi $\mathbf{8 3 0 0 0 0 ,}$

People's Republic of China
Correspondence: Ailiman Mahemuti Department of Cardiovascular Medicine, The First Affiliated Hospital of Xinjiang Medical University, Urumqi 830000,

People's Republic of China

Tel +86-99l-4366426

Email xinjiangailiman@।63.com
Background: Venous thromboembolism (VTE) is the third most common cause of cardiovascular death worldwide, following coronary heart disease and stroke, and many risk factors for VTE are not yet clear. Our study investigated the association between multiple inflammatory gene polymorphisms and VTE prognosis, aiming to find a new predictor of VTE prognosis.

Methods: Based on our previous studies, we detected the plasma levels of serum amyloid A protein (SAA), interleukin-1 (IL-1) and tumor necrosis factor-a (TNF-a) and their 8 gene polymorphisms by ELISA and a multiplex ligation detection reaction (iMLDR) method in 284 patients with VTE. All subjects were followed up for 5 years.

Results: The 5-year follow-up results of this study showed that 62 of the 284 patients $(21.83 \%)$ had reached the endpoint (all-cause death). Kaplan-Meier survival analyses revealed that the mortality rate of VTE patients with a high Simplified Pulmonary Embolism Severity Index (SPESI) score and carrying IL-1 rs1800587 mutation genotypes was significantly increased (log-rank $p=0.000$ and 0.034 respectively). The multifactor Cox regression results confirmed that the mortality rate of patients who carrying IL-1 rs 1800587 mutation genotypes was significantly increased ( $\mathrm{HR}=2.982 ; 95 \% \mathrm{CI}: 1.681-5.100)$. The mortality rate of those carrying IL-1 rs1143634 mutation genotypes was significantly decreased $(\mathrm{HR}=0.294 ; 95 \% \mathrm{CI}: 0.132-0.652)$. There were no significant differences in mortality rates between wild-type and mutant genotypes of IL-1 rs1143634, IL-1 rs2234650, SAA rs11603089, and TNF- $\alpha$ rs1800629 (P>0.05).

Conclusion: A high SPESI score and the presence of the IL-1 rs1800587 mutant genotype predict shorter survival in patients with VTE, whereas the IL-1 rs1143634 genotype is associated with a lower mortality rate. Screening for mutations in inflammation-related genes has prognostic value in the clinical management of VTE.

Keywords: venous thromboembolism, VTE, inflammatory markers, gene polymorphism, prognosis

\section{Introduction}

Venous thromboembolism (VTE) is the third most common cause of cardiovascular death, following coronary heart disease and stroke, accounting for 5.4 million deaths worldwide each year. Due to the lack of specific clinical manifestations, VTE is often overlooked by clinicians, and in some cases is not confirmed until autopsy. ${ }^{1-3}$ Interventions for common risk factors for VTE failed to prevent its occurrence and poor prognosis, and anticoagulation therapy also showed individual differences among patients. Therefore, it is urgent to elucidate the internal mechanism of VTE from a new perspective. 
Recent studies suggest that venous thromboembolic disease may be a type of chronic nonspecific inflammatory disease. VTE can cause circulatory instability, insufficient perfusion, hypoxia and ischemia, which in turn leads to blood clotting, further exacerbates inflammation following a thrombotic event. ${ }^{4-11}$ To date, there have been any research on the association between inflammatory gene polymorphisms and the prognosis of VTE. Our previous study ${ }^{12}$ showed that plasma levels of serum amyloid A protein (SAA), interleukin-1 (IL-1) and tumor necrosis factor-a (TNF-a) in the VTE group were significantly higher than those in the control group. The TT genotype of the IL-1 rs2234650 variant was an independent risk factor for VTE. Whereas the AA genotype of IL-1 rs1800587 is an independent protective factor for VTE. In the present study, we investigated additional risk factors for VTE by analyzing the association between mutations in inflammatory related genes and the long-term outcome of VTE patients in a 5-year follow-up study.

\section{Materials and Methods}

\section{Study Population}

Our team has followed a cohort of VTE patients in Xinjiang since 2015. At the same time, clinical data have been collected from all of the patients. All subjects were followed up every 3 months at outpatient clinics or through telephone or email contact. The main endpoint of this study was all-cause death. We regularly followed up with the VTE patients in a variety of ways; thus, the endpoint events were easier to obtain, and the loss of patients was avoided to the greatest extent. The cohort included 284 patients diagnosed with VTE $^{13}$ after hospitalization between January 2015 and January 2019 who were selected from the VTE specimen bank of The First Affiliated Hospital of Xinjiang Medical University Research Library. There were 134 males and 150 females, with an average age of $54.82 \pm 15.47$ years. A total of 268 healthy subjects whose general information, such as age and sex, matched with that of the case group was selected as the control group. There were 122 males and 146 females, with an average age of $54.21 \pm 15.40$ years.

\section{Genotyping of the IL-I, SAA, and TNF- $\alpha$ Gene Variants}

Using Shanghai Tianhao Company's improved multiplex ligation detection reaction (iMLDR) Multiple Allelic Typing Kit, 8 genotypes were screened for in all samples with capillary peak electrophoresis using the iMLDR technique. $^{12,14}$

\section{Statistical Analysis}

The statistical software package SPSS 23.0 (International Business Machines Corporation, 2015) was used for the statistical analysis. The mean \pm standard deviation and a $t$-test were used for comparisons between groups. A chisquare test was used to compare the categorical variables between groups. Genotypes and genotype frequencies of the case and control groups were compared with the predicted Hardy-Weinberg equilibrium value using a chisquare test. The Kaplan-Meier survival analysis and Log rank test were used to evaluate the difference in survival time between groups. A Cox regression model was used to analyze the risk factors related to prognosis. The hazard ratio (HR) was calculated by cross tabulation and Cox regression to determine the relative risk of mortality. A two-tailed P-value of $<0.05$ was considered indicative of statistical significance.

\section{Results}

\section{Differences in the General Clinical} Information of VTE Patients in the

\section{Survival and Endpoint Event Groups During Follow-Up}

Our study included 284 patients with VTE who were followed up through 4075 visits over a period of 3-60 months. Sixty two patients reached the primary endpoint of the study, accounting for $21.83 \%$ of the 284 VTE patients, with a median survival time of 49 months. There were no significant differences in age, sex, smoking history, hypertension, diabetes, coronary heart disease (CHD), chronic obstructive pulmonary disease (COPD), chronic heart failure (CHF), or obesity among the VTE survival and endpoint event groups $(\mathrm{P}>0.05)$. The red cell volume distribution width ( $\mathrm{RDW})(\mathrm{P}=0.000)$, $\mathrm{D}$-dimer (D-D) $(\mathrm{P}=0.002)$, and brain natriuretic peptide (BNP) $(\mathrm{P}=0.000)$ levels were significantly different between the two groups. (Table 1)

\section{Differences in the Simplified Pulmonary Embolism Severity Index (SPESI) Scores of VTE Patients in the Survival and Endpoint Event Groups During Follow-Up}

The SPESI score is a condensed scoring standard based on the Pulmonary Embolism Severity Index (PESI) score, ${ }^{15}$ which is based on the following 6 indicators: age $>80$ 
Table I Comparison of General Clinical Informations and Inflammatory Biomarkers Between Survival and Event Group

\begin{tabular}{|c|c|c|c|}
\hline Variables & Survival Group $(n=222)$ & Event Group $(n=62)$ & $\mathbf{P}$ \\
\hline \multicolumn{4}{|l|}{ Clinical Informations } \\
\hline Age & $55.35 \pm 15.33$ & $52.94 \pm 16.06$ & 0.280 \\
\hline Gender,male, n (\%) & $104(46.8)$ & $30(48.4)$ & 0.830 \\
\hline Smoking, n (\%) & $107(48.2)$ & $22(35.5)$ & 0.075 \\
\hline Hypertension, n (\%) & $110(49.5)$ & $26(41.9)$ & 0.289 \\
\hline Diabetes, n (\%) & $40(18.0)$ & $12(19.4)$ & 0.810 \\
\hline CHD, n (\%) & $52(23.4)$ & $8(12.9)$ & 0.073 \\
\hline COPD, n (\%) & $54(24.3)$ & $22(35.5)$ & 0.079 \\
\hline CHF, n (\%) & $36(16.2)$ & $12(19.4)$ & 0.560 \\
\hline Obesity (BMI $\geq 30$ ),n (\%) & $93(41.9)$ & $32(51.6)$ & 0.173 \\
\hline RDW & $14.1218 \pm 1.449$ & $15.1225 \pm 1.7378$ & 0.000 \\
\hline D-D & $613.3198 \pm 693.6920$ & $989.1774 \pm|248.8| 25$ & 0.002 \\
\hline BNP & $|408.8665 \pm 233| .975 \mid$ & $284|.6387 \pm 406| .8884$ & 0.000 \\
\hline \multicolumn{4}{|l|}{ Inflammatory Biomarkers } \\
\hline $\mathrm{SAA}(\mu \mathrm{g} / \mathrm{mL})$ & $12.6382 \pm 8.1807$ & $14.2619 \pm 10.6790$ & 0.007 \\
\hline IL-I (pg/mL) & $35.2626 \pm 18.7848$ & $39.1337 \pm 22.8538$ & 0.000 \\
\hline TNF- $\alpha(p g / m L)$ & $21.0263 \pm 12.4902$ & $27.5735 \pm 24.1814$ & 0.000 \\
\hline CRP $(\mathrm{mg} / \mathrm{l})$ & $3.5182 \pm 4.3508$ & $6.9329 \pm 9.3631$ & 0.000 \\
\hline $\mathrm{ST} 2(\mathrm{pg} / \mathrm{mL})$ & $324.7432 \pm 147.5317$ & $375.6827 \pm 223.0113$ & 0.034 \\
\hline IL-6 (pg/mL) & $14.7225 \pm 9.8379$ & $15.2374 \pm 12.1476$ & 0.112 \\
\hline
\end{tabular}

Abbreviations: CHD, coronary heart disease; COPD, chronic obstructive pulmonary disease; CHF, chronic heart failure; RDW, red cell volume distribution width; D-D, D-dimer; BNP, brain natriuretic peptide; SAA, serum amyloid A protein; IL-I, interleukin-I; TNF- $\alpha$, tumor necrosis factor- $\alpha$; CRP, C-reaction protein; ST2, suppression of tumorigenicity 2; IL-6, interleukin-6.

years, history of malignant tumors, history of concomitant heart failure and/or chronic lung disease, systolic blood pressure $<100 \mathrm{mmHg}$, heart rate $\geq 110$ beats $/ \mathrm{min}$, and oxygen saturation $<90 \%$. Each positive item is assigned 1 point, and a total score of 0 point indicates low risk, while any positive score is considered high risk. As shown in Figure 1, patients with higher SPESI scores had a higher mortality rate $(\log \operatorname{rank} \mathrm{P}=0.000)$. (Figure 1 )

\section{Differences in the Levels of Inflammatory Markers in VTE Patients in the Survival and End-Point Event Groups During Follow-Up}

Compared with patients in the VTE survival group, patients in the VTE endpoint event group had significantly higher plasma SAA ( $\mathrm{P}=0.007)$, IL-1 $(\mathrm{P}=0.000)$, TNF-a $(\mathrm{P}=0.000), \mathrm{C}-$ reaction protein $(\mathrm{CRP})(\mathrm{P}=0.000)$, and suppression of tumorigenicity 2 protein (ST2) $(\mathrm{P}=0.034)$ levels. The interleukin-6 (IL-6) levels were not significantly different between the two groups $(\mathrm{P}=0.112)$. (Table 1)
Differences in SAA, IL-I and TNF-A Gene Polymorphisms Among VTE Patients in the Survival and End-Point Event Groups During Follow-Up

Among the 8 variants selected in our study, only the CC genotype was present in the TNF-a rs55933305 variant, and only the TT genotype was present in the SAA rs2229338 variant. The genotype distributions of all genotype, except for SAA rs713332, were consistent with Hardy-Weinberg equilibrium. Because it did not conform to Hardy-Weinberg equilibrium, the SAA rs713332 variant was excluded from the follow-up statistical analysis. As shown in Table 2 and Figure 2, the Kaplan-Meier survival analysis results indicated that patients carrying the GA and AA mutant genotypes have a higher mortality rate than those carrying the IL-1 rs1800587 wild-type GG genotype (log rank $\mathrm{P}=0.034$ ). There were no significant differences in survival curves between the wild-type and mutant genotypes of the IL-1 rs1143634 (log rank $\mathrm{P}=0.148$ ), IL-1 rs2234650 (log rank $\mathrm{P}=0.224)$, SAA rs 11603089 ( $\log \operatorname{rank} \mathrm{P}=0.673)$, and TNF- $\alpha$ rs1800629 (log rank $\mathrm{P}=0.969)$ variants. (Table 3, Figure 2) 


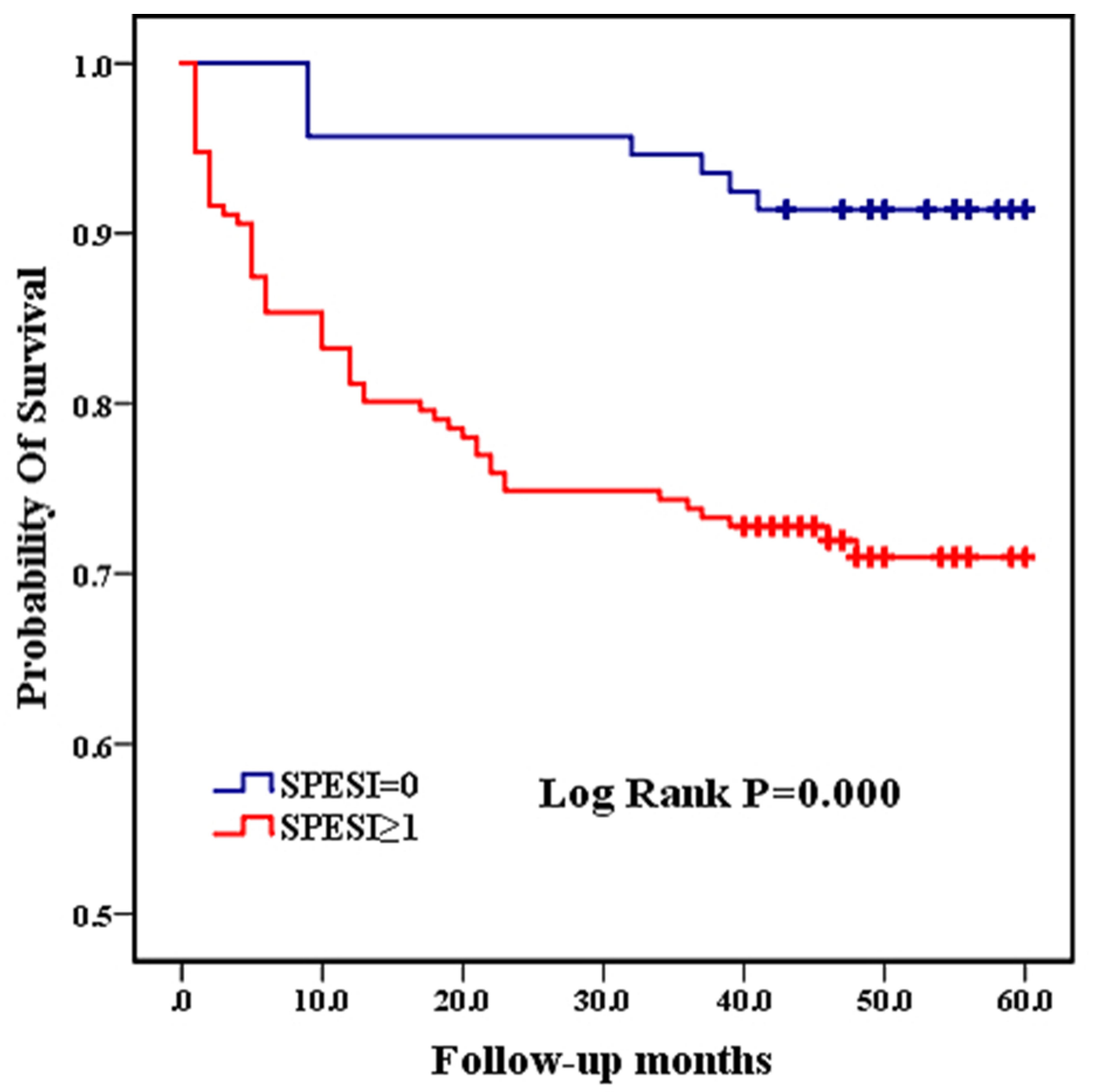

Figure I Comparison of Kaplan-Meier curves between high and low SPESI groups.

\section{Multifactor Cox Regression Analysis of VTE Risk Factors}

As shown in Table 2, the results of the multivariate Cox regression analysis still confirmed that the mutant genotype of IL-1 rs1800587 was associated with an increased risk of VTE mortality $(\mathrm{HR}=2.982 ; 95 \% \mathrm{CI}: 1.681-5.100)$. On the other hand, patients carrying the IL-1 rs1143634 mutant genotype had a lower mortality rate than patients with the wildtype allele $(\mathrm{HR}=0.294 ; 95 \%$ CI: $0.132-0.652)$ (Table 2$)$.

\section{Discussion}

In this study, 284 VTE patients were followed up for 5 years. Sixty-two patients reached the primary endpoint of the study, accounting for $21.83 \%$ of the 284 VTE patients, with a median survival time of 49 months, which is in accordance with the results of previously published studies. ${ }^{16,17}$ Our research suggests that the proportion of risk factors such as age, sex, smoking history, hypertension, diabetes, and coronary heart disease in the VTE endpoint event group was not significantly different from that in the VTE survival group. Therefore, it is believed that VTE may have undiscovered risk factors that affect its prognosis.

The SPESI is a reliable prognostic scoring system recommended in VTE guidelines. ${ }^{13}$ In the present study, VTE patients with a high SPESI score had an increased mortality rate, suggesting that our clinicians should pay attention to the use of the VTE prognostic evaluation system in clinical practice. At the same time, we should require more rigorous follow-up and standardized long-term guidance for high-risk patients to prolong patients survival time.

RDW reflects variability in red blood cell size and is closely related to cardiovascular disease, chronic heart failure, acute sepsis, septic shock, and poor prognosis of VTE. ${ }^{18-20}$ We observed that the endpoint event group had higher RDW levels and implying that VTE patients with elevated RDW levels may have a higher risk of death, as demonstrated in other studies. $^{21,22}$ At present, the potential biomolecular 
Table 2 Multivariate Factor COX Regression Analysis of VTE Risk Factors

\begin{tabular}{|l|l|l|l|}
\hline Gene Variants & Hazard Ratio & $\mathbf{9 5 \%} \mathbf{C I}$ & $\mathbf{P}$ \\
\hline $\begin{array}{l}\text { IL-I rs I800587 } \\
\text { (GG/GA+AA) }\end{array}$ & 2.928 & $1.68 I-5.100$ & 0.000 \\
\hline $\begin{array}{l}\text { IL-I rs II43634 } \\
\text { (GG/GA+AA) }\end{array}$ & 0.294 & $0.132-0.652$ & 0.003 \\
\hline $\begin{array}{l}\text { IL-I rs2234650 } \\
\text { (CC/CT+TT) }\end{array}$ & 0.595 & $0.352-1.004$ & 0.052 \\
\hline $\begin{array}{l}\text { SAA rs II603089 } \\
(A A / G A+G G)\end{array}$ & 1.095 & $0.653-1.836$ & 0.730 \\
\hline $\begin{array}{l}\text { TNF- } \alpha \text { rs I800629 } \\
\text { (GG/GA+AA) }\end{array}$ & 1.027 & $0.553-1.908$ & 0.932 \\
\hline
\end{tabular}

Abbreviations: IL-I, interleukin-I; SAA, serum amyloid A protein; TNF- $\alpha$, tumor necrosis factor- $\alpha$.

mechanism of the relationship between the RDW and VTE is unclear, but it is widely acknowledged that high RDW is associated with a prethrombotic state, induction of inflammation and changes in blood viscosity. ${ }^{21,22}$ D-D is a globally recognized predictor of VTE, but the correlation between D-D and VTE prognosis is inconclusive. In this study, D-D level was higher in the VTE endpoint event group than in the survival group, suggesting that it also has predictive value for VTE-associated mortality. As a volume-sensitive neurohormone, BNP is closely related to right ventricular dilatation, right ventricular dysfunction, and pressure load, especially in acute pulmonary embolism. Thrombosis blocking the pulmonary artery, can inhibit th the release of humoral factors, and vascular hypoxia, causing pulmonary vasoconstriction and increased right ventricular wall tension, resulting in elevated levels of BNP, which has been linked to poor prognosis of VTE. ${ }^{23}$ Our results showed that the BNP level in the endpoint event group was higher, which is consistent with the results of the above study. Therefore, in our clinical practice, we cannot ignore the close relationship between

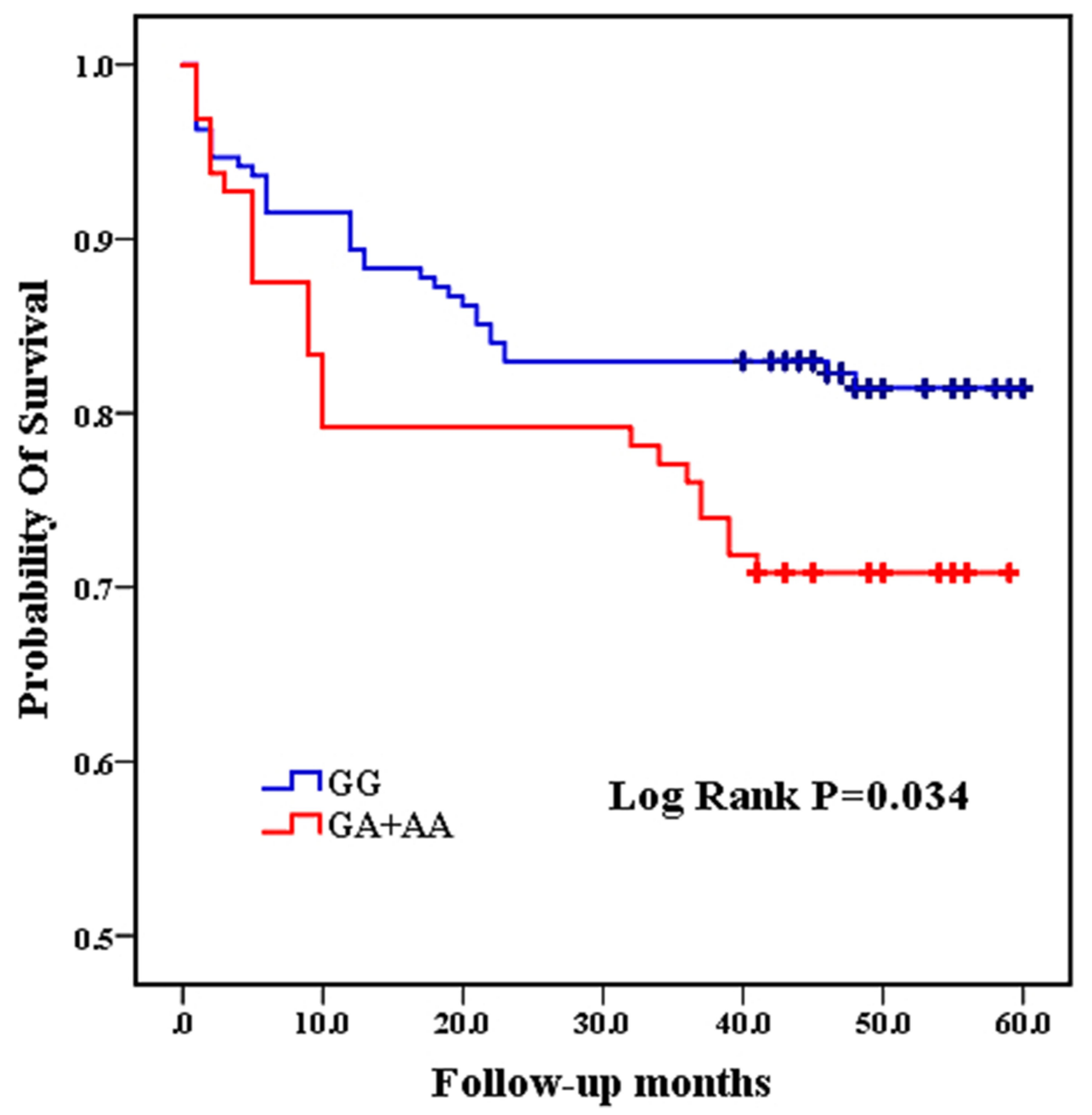

Figure 2 Comparison of Kaplan-Meier curves between GG and GA+AA genotypes of IL-I rs I800587. 
Table 3 Comparison of Log Rank $\mathrm{P}$ value Between Wild and Mutation Types of Inflammatory Genes

\begin{tabular}{|l|l|l|l|}
\hline Gene & Wild Type & Mutation Type & Log Rank P \\
\hline IL-I rsI800587 & GG & GA+AA & 0.034 \\
\hline IL-I rsII43634 & GG & GA+AA & 0.148 \\
\hline IL-I rs2234650 & CC & CT+TT & 0.224 \\
\hline SAA rsII603089 & AA & GA+GG & 0.673 \\
\hline TNF- $\alpha$ rsI800629 & GG & GA+AA & 0.969 \\
\hline
\end{tabular}

Abbreviations: IL-I, interleukin-I; SAA, serum amyloid A protein; TNF- $\alpha$, tumor necrosis factor- $\alpha$.

RDW, D-D, BNP and other biochemical indicators and VTE mortality.

With the development of molecular biology, a large number of evidence-based studies have confirmed the correlation between inflammation and VTE. ${ }^{4-11}$ The CANTOS trial, a large sample, multicenter, randomized study, ${ }^{24}$ verified the effectiveness of anti-inflammatory treatment for VTE. IL-1, SAA, IL-6, TNF- $\alpha$, and CRP, as a class of pro-inflammatory factors, are important mediators of inflammation activation, and after inflammation, their activation may lead to slowed blood flow, vascular endothelial damage, and coagulation disorders that promote the occurrence of VTE. ${ }^{12,25-28}$ IL-1, SAA, TNF- $\alpha$, and CRP levels were elevated in the VTE endpoint event group in the current study, suggesting that the poor prognosis caused by intense vascular injury after inflammation activation. As an important signal of IL-33/ST2L axis activation, ST2 is triggered and expressed during fibrosis, tissue damage, inflammation activation and cardiovascular remodeling. ST2 has become a new indicator for predicting the occurrence and prognosis of inflammatory, immune and cardiovascular diseases such as heart failure, aortic dissection and autoimmune diseases. ${ }^{29-31}$ We found that the ST2 level in the VTE endpoint event group increased significantly. Therefore, ST2 level was increased in the endpoint event group, it can potentially serve as a prognostic indicator in VTE.

Genetics may play a causative role in $60 \%$ of VTE cases, although most genetic factors are still unknown. ${ }^{32,33}$ Coagulation factor $\mathrm{V}$ Leiden mutations, prothrombin G20210A mutations, and protein $\mathrm{C}$ and protein $\mathrm{S}$ defects are known genetic risk factors for VTE. ${ }^{34,35}$ And single nucleotide polymorphisms are useful markers for analyzing the genetic basis of a particular phenotype, because of its economic and time-saving benefits. Our previous study ${ }^{12}$ and others demonstrated that IL-1 rs2234650, ${ }^{36} \operatorname{rs} 1800587,{ }^{37}$ rs $1143634^{38,39}$ variant polymorphisms are closely related to the occurrence of VTE. Our single-factor Kaplan-Meier survival analysis and multifactor Cox regression analysis results showed that those carrying the IL-1 rs1800587 mutation genotypes have a higher mortality rate. Multifactor Cox regression results show that the mortality rate of VTE patients carrying IL-1 rs1143634 mutation genotypes had a lower risk of mortality. These results of the study confirmed the close relationship between the polymorphisms of inflammatory genes and the prognosis of VTE.

Our study had certain limitations, such as the relatively small sample size and few genetic variants were analyzed. Additional studies in a larger cohort are needed in order to validate the distinct mechanisms underlying the associations between different IL-1 gene polymorphisms and VTE. VTE caused by IL-1 gene mutation is more complex, which may involve changes in gene structure, protein signal transduction and other related contents. So far, the molecular mechanism has not been elucidated.

\section{Conclusion}

In conclusion, the results presented here demonstrate that that VTE prognosis is closely related to inflammatory markers and their gene polymorphisms. Additional factors contributing to poor prognosis in VTE are vascular endothelial injury, coagulation and fibrinolysis disturbance after inflammation activation. In clinical practice, rationally analyzing various clinical indicators and incorporating the SPESI scoring system, BNP, D-D, RDW, inflammation markers into the VTE prognosis indicator system may provide early warnings of death in VTE patients.

Like most complex diseases and disorders, VTE is mostly caused by the interaction of multiple minor genes and the joint action of environmental factors. Candidate gene association studies based on a limited sample are one of the main approaches used to identify susceptibility genes for complex diseases. Our findings showed that 2 variants of IL-1 rs1800587 and rs1143634 have opposite prognostic significance for VTE. Applying personalized management strategies to high risk patients according to differences in genotype may potentially provide a theoretical basis for the exploration of accurate prevention and gene therapy intervention strategies of VTE in later clinical practice.

\section{Data Sharing Statement}

The datasets generated during and/or analyzed in the current study are available from the corresponding author on reasonable request. 


\section{Ethics Statement}

The authors are accountable for all aspects of the work in ensuring that questions related to the accuracy or integrity of any part of the work are appropriately investigated and resolved. The Ethics Committee of the First Affiliated Hospital of Xinjiang Medical University reviewed and approved the ethics of this study (No. 20150716-06). This study was carried out in accordance with the principles outlined in the Declaration of Helsinki. Each patient was provided with a description of the study and signed a written informed consent form.

\section{Acknowledgments}

We thank all participants in the study.

\section{Funding}

This work was supported financially by the National Natural Science Fund of China (81560803).

\section{Disclosure}

The authors have no conflicts of interest to declare.

\section{References}

1. Konstantinides SV, Meyer G, Becattini C, et al. 2019 ESC guidelines for the diagnosis and management of acute pulmonary embolism developed in collaboration with the European Respiratory Society (ERS). Eur Heart J. 2020;41(4):543-603. doi:10.1093/eurheartj/ehz405

2. Goldhaber SZ, Bounameaux H. Pulmonary embolism and deep vein thrombosis. Lancet (London, England). 2012;379(9828):1835-1846. doi:10.1016/s0140-6736(11)61904-1

3. Hochhegger B, Marchiori E, Irion K. Acute pulmonary embolism. $N$ Engl $J$ Med. 2010;363(20):1974-1975. doi:10.1056/ NEJMc1009061

4. Poredos P. Interrelationship between venous and arterial thrombosis. Int Angiol. 2017;36(4):295-298. doi:10.23736/s0392-9590.17.03820-2

5. Hansson GK. Inflammation and atherosclerosis: the end of a controversy. Circulation. 2017;136(20):1875-1877. doi:10.1161/ CIRCULATIONAHA.117.030484

6. Saghazadeh A, Rezaei N. Inflammation as a cause of venous thromboembolism. Crit Rev Oncol Hematol. 2016;99:272-285. doi:10.1016/j.critrevonc.2016.01.007

7. Vazquez-Garza E, Jerjes-Sanchez C, Navarrete A, Joya-Harrison J, Rodriguez D. Venous thromboembolism: thrombosis, inflammation, and immunothrombosis for clinicians. J Thromb Thrombolysis. 2017;44(3):377-385. doi:10.1007/s11239-017-1528-7

8. Riva N, Donadini MP, Ageno W. Epidemiology and pathophysiology of venous thromboembolism: similarities with atherothrombosis and the role of inflammation. Thromb Haemost. 2015;113(6):1176-1183. doi:10.1160/th14-06-0563

9. Bakirci EM, Topcu S, Kalkan K, et al. The role of the nonspecific inflammatory markers in determining the anatomic extent of venous thromboembolism. Clin Appl Thromb Hemost. 2015;21(2):181-185. doi:10.1177/1076029613494469

10. Poredos P, Jezovnik MK. The role of inflammation in venous thromboembolism and the link between arterial and venous thrombosis. Int Angiol. 2007;26(4):306-311.
11. Levi M, van der Poll T, Büller HR. Bidirectional relation between inflammation and coagulation. Circulation. 2004;109(22):2698-2704. doi:10.1161/01.cir.0000131660.51520.9a

12. Abuduhalike R, Sun J, Zhao L, Mahemuti A. Correlation study of venous thromboembolism with SAA, IL-1, and TNF-a levels and gene polymorphisms in Chinese population. $J$ Thorac Dis. 2019;11 (12):5527-5534. doi:10.21037/jtd.2019.11.26

13. Konstantinides SV, Meyer G, Becattini C, et al. 2019 ESC guidelines for the diagnosis and management of acute pulmonary embolism developed in collaboration with the European Respiratory Society (ERS): the Task Force for the diagnosis and management of acute pulmonary embolism of the European Society of Cardiology (ESC). Eur Respir J. 2019;54(3):1-68. doi:10.1183/ 13993003.01647-2019

14. Shi Z, Zhang Q, Chen H, et al. Association of CD40 gene polymorphisms with susceptibility to neuromyelitis optica spectrum disorders. Mol Neurobiol. 2017;54(7):5236-5242. doi:10.1007/ s12035-016-0070-5

15. Jiménez D, Aujesky D, Moores L, et al. Simplification of the pulmonary embolism severity index for prognostication in patients with acute symptomatic pulmonary embolism. Arch Intern Med. 2010;170 (15):1383-1389. doi:10.1001/archinternmed.2010.199

16. Tagalakis V, Patenaude V, Kahn SR, Suissa S. Incidence of and mortality from venous thromboembolism in a real-world population: the Q-VTE study cohort. Am J Med. 2013;126(9):832.e813-832. e821. doi:10.1016/j.amjmed.2013.02.024

17. Yang Y, Liang L, Zhai Z, et al. Pulmonary embolism incidence and fatality trends in chinese hospitals from 1997 to 2008: a multicenter registration study. PLoS One. 2011;6(11):e26861. doi:10.1371/journal.pone. 0026861

18. Tonelli M, Sacks F, Arnold M, Moye L, Davis B, Pfeffer M. Relation between red blood cell distribution width and cardiovascular event rate in people with coronary disease. Circulation. 2008;117 (2):163-168. doi:10.1161/circulationaha.107.727545

19. Felker GM, Allen LA, Pocock SJ, et al. Red cell distribution width as a novel prognostic marker in heart failure: data from the CHARM program and the Duke Databank. J Am Coll Cardiol. 2007;50 (1):40-47. doi:10.1016/j.jacc.2007.02.067

20. Kim CH, Park JT, Kim EJ, et al. An increase in red blood cell distribution width from baseline predicts mortality in patients with severe sepsis or septic shock. Critical Care (London, England). 2013;17(6):R282. doi:10.1186/cc13145

21. Zorlu A, Bektasoglu G, Guven FM, et al. Usefulness of admission red cell distribution width as a predictor of early mortality in patients with acute pulmonary embolism. Am J Cardiol. 2012;109 (1):128-134. doi:10.1016/j.amjcard.2011.08.015

22. Zöller B, Melander O, Svensson P, Engström G. Red cell distribution width and risk for venous thromboembolism: a population-based cohort study. Thromb Res. 2014;133(3):334-339. doi:10.1016/j. thromres.2013.12.013

23. Binder L, Pieske B, Olschewski M, et al. N-terminal pro-brain natriuretic peptide or troponin testing followed by echocardiography for risk stratification of acute pulmonary embolism. Circulation. 2005;112(11):1573-1579. doi:10.1161/circulationaha. 105.552216

24. Ridker PM, Everett BM, Thuren T, et al. Antiinflammatory therapy with canakinumab for atherosclerotic disease. $N$ Engl J Med. 2017;377(12):1119-1131. doi:10.1056/NEJMoa1707914

25. Christiansen SC, Naess IA, Cannegieter SC, Hammerstrom J, Rosendaal FR, Reitsma PH. Inflammatory cytokines as risk factors for a first venous thrombosis: a prospective population-based study. PLoS Med. 2006;3(8):e334. doi:10.1371/journal. pmed.0030334

26. Deguchi H, Elias DJ, Navarro S, Espana F, Griffin JH. Elevated serum amyloid A is associated with venous thromboembolism. Thromb Haemost. 2013;109(2):358-359. doi:10.1160/th12-10-0722 
27. Reitsma PH, Rosendaal FR. Activation of innate immunity in patients with venous thrombosis: the leiden thrombophilia study. $J$ Thromb Haemost. 2004;2(4):619-622. doi:10.1111/j.15387836.2004.00689.x

28. Fox EA, Kahn SR. The relationship between inflammation and venous thrombosis. A systematic review of clinical studies. Thromb Haemost. 2005;94(2):362-365. doi:10.1160/th05-04-0266

29. Bayes-Genis A, Zhang Y, Ky B. ST2 and patient prognosis in chronic heart failure. Am J Cardiol. 2015;115(7):64b-69b. doi:10.1016/j. amjcard.2015.01.043

30. Wang Y, Tan X, Gao H, et al. Magnitude of soluble ST2 as a novel biomarker for acute aortic dissection. Circulation. 2018;137 (3):259-269. doi:10.1161/circulationaha.117.030469

31. Kuroiwa K, Arai T, Okazaki H, Minota S, Tominaga S. Identification of human ST2 protein in the sera of patients with autoimmune diseases. Biochem Biophys Res Commun. 2001;284(5):1104-1108. doi:10.1006/bbrc.2001.5090

32. Heit JA, Phelps MA, Ward SA, Slusser JP, Petterson TM, De Andrade M. Familial segregation of venous thromboembolism. $J$ Thromb Haemost. 2004;2(5):731-736. doi:10.1111/j.15387933.2004.00660.x

33. Larsen TB, Sorensen HT, Skytthe A, Johnsen SP, Vaupel JW, Christensen K. Major genetic susceptibility for venous thromboembolism in men: a study of Danish twins. Epidemiology (Cambridge, Mass). 2003;14(3):328-332. doi:10.1097/01.EDE.0000060457.51194.BC
34. Crowther MA, Kelton JG. Congenital thrombophilic states associated with venous thrombosis: a qualitative overview and proposed classification system. Ann Intern Med. 2003;138(2):128-134. doi:10.7326/ 0003-4819-138-2-200301210-00014

35. Martinelli I, Cattaneo M, Taioli E, De Stefano V, Chiusolo P, Mannucci PM. Genetic risk factors for superficial vein thrombosis. Thromb Haemost. 1999;82(10):1215-1217. doi:10.1055/s-00371614362

36. Beckers MM, Ruven HJ, Haas FJ, et al. Single nucleotide polymorphisms in inflammation-related genes are associated with venous thromboembolism. Eur J Intern Med. 2010;21(4):289-292. doi:10.1016/j.ejim.2010.04.001

37. van Aken BE, den Heijer M, Bos GM, van Deventer SJ, Reitsma PH. Recurrent venous thrombosis and markers of inflammation. Thromb Haemost. 2000;83(4):536-539. doi:10.1055/s-0037-1613858

38. Zee RY, Glynn RJ, Cheng S, Steiner L, Rose L, Ridker PM. An evaluation of candidate genes of inflammation and thrombosis in relation to the risk of venous thromboembolism: the women's genome health study. Circ Cardiovasc Genet. 2009;2(1):57-62. doi:10.1161/circgenetics.108.801969

39. Zee RY, Bubes V, Shrivastava S, Ridker PM, Glynn RJ. Genetic risk factors in recurrent venous thromboembolism: a multilocus, population-based, prospective approach. Clin Chim Acta. 2009;402 (1-2):189-192. doi:10.1016/j.cca.2009.01.011.

\section{Publish your work in this journal}

The International Journal of General Medicine is an international, peer-reviewed open-access journal that focuses on general and internal medicine, pathogenesis, epidemiology, diagnosis, monitoring and treatment protocols. The journal is characterized by the rapid reporting of reviews, original research and clinical studies across all disease areas. The manuscript management system is completely online and includes a very quick and fair peer-review system, which is all easy to use. Visit http://www.dovepress.com/ testimonials.php to read real quotes from published authors. 